\title{
Sueño y verdad en "Las ruinas circulares" de Borges*
} Dream and Truth in Borges' "The Circular Ruins"

\section{Esteban Radiszcz S.}

Universidad de Chile

Resumen. A partir del análisis de "Las ruinas circulares" de Jorge Luis Borges se aborda el enigma del sueño en el sueño. Se sostiene que, en tanto formación de inconsciente, el sueño al interior del sueño concierne a la verdad en su estructura de ficción. Pero su singular formulación redoblada sitúa al sueño soñado en un más allá de lo simbólico capaz de realizar una decidida afirmación $\{$ Bejahung\} de lo real $\{$ Realität $\}$. Simbólico y real confluirían en el sueño dentro del sueño en función del lugar que, en él, le cabe al objeto $a$ en su relación al deseo del Otro.

Palabras clave: Sueño en el sueño, Verdad, Real.

From the analysis of "The Circular Ruins" by Jorge Luis Borges, the enigma of sleep is addressed in the dream. It is argued that, as an unconscious formation, the dream formulation puts the drea the truth in its fictive structure. But its unique redoubled formulation puts the dream dreamed beyond the symbolic, allowing a strong affirmation $\{$ Bejahung $\}$ of the real \{Realiat\}. Symbollc and Real coalesce in the dream within the dream in function of the place in which an object belongs in its relation to

Keywords: Dream within the dream, Truth, Real.

* Este artículo forma parte del Proyecto Fondecyt Regular 2013 № 1131144, titulado Este trabajo se integra a los resultados del proyecto "Políticas de la subjetividad: malestar en la cultura, salud mental y vida cotidiana en Chile", financiado por el Fondo de Investigación/ Creación (2012-2014) de la Iniciativa Bicentenario de revitalización de las Humanidades, las Artes, las Ciencias Sociales y Ciencias de la Comunicación de la Universidad de Chile. 
"En el sueño del hombre que soñaba, el soñado se despertó"

J.L. Borges, "Las ruinas circulares" (850)

\section{Preámbulo: sobre sueño y literatura}

Pretender examinar el lugar que le cabe al sueño en la literatura está lejos de ser una magra empresa. Como se sabe, el sueño es una pieza central, tanto para el romanticismo alemán e inglés, como para la poesía francesa de fines del siglo XIX y el surrealismo. No obstante, lejos de limitarse a Novalis, Coleridge, Nerval o Aragon, el sueño en la literatura tiene una larga historia que se remonta a la antigüedad y se prosigue aún en nuestros días. En tal sentido, cabría también mencionar las visiones de la Iliada, la Odisea y la Eneida, los relatos oníricos de la Divina Comedia o del Persiles y, más actualmente, los sueños narrados por Vian, Cortázar o Bolaño.

Por cierto, nuestro propósito no aspira a tal envergadura y se limita a algunas observaciones que, articuladas en un diálogo entre psicoanálisis y literatura, no reclaman vastas generalizaciones y se concentran en un breve opúsculo de Borges publicado en 1940. Sin duda, nos será de provecho si, en esta menos ambiciosa tarea, procedemos al modo del propio Borges cuando, ante el "[d]esvarío laborioso [...] de componer vastos libros", prefería ser "[m]ás razonable, más inepto, más haragán" en su opción por concisas "notas" que, no por ello, fuesen menos precisas ("Prólogo [a El jardín]" 829).

\section{El sueño de un hombre soñado}

Originalmente publicado en la revista Sur, "Las ruinas circulares" es un cuento que relata la sobrenatural historia de un "hombre gris" que, llegado a un derruido y abandonado templo, se dedica a "soñar un hombre" para "imponerlo a la realidad" (848). El protagonista logra soñar un anfiteatro lleno de "alumnos taciturnos" que seguían sus lecciones de anatomía, cosmografía y magia. De entre ellos, escoge a uno y, licenciando el "colegio ilusorio", se dedica exclusivamente al elegido. No obstante, un día no sueña y por otros tantos queda insomne. Decide seguir un método diverso: abandona la premeditación de soñar, apela a "dioses planetarios", purifica su cuerpo en el río y pronuncia "sílabas de un nombre poderoso" (849).

Vuelto a dormir, sueña "con un corazón que latía [...] en la penumbra de un cuerpo humano aún sin cara ni sexo". Poco a poco lo percibe con más evidencia hasta obtener la visión de otros órganos y, al fin, soñarlo íntegro (849-50). Pero su elemental "Adán de sueño" yace dormido y sin habla, por lo que se encomienda a la efigie del templo y demanda su socorro. Al crepúsculo, sueña viva a la estatua divina que, entonces, le concede animar al hombre, indicando que, a excepción del Fuego y el soñador, será pensado humano y no fantasma. $Y$, a la sazón, despierta en el sueño la criatura cuyo soñador denomina hijo y, gradualmente, lo acostumbra a la realidad para, llegado el día, enviarlo a los despojos de otro templo desierto, donde glorificar a la sagrada efigie. Antes, no obstante, infunde en su hijo el olvido total de aquellos años "para que no supiera nunca que era un fantasma" (850). 
Tiempo después, el soñador recibe noticias "de un mágico hombre de un templo del Norte, capaz de hollar el fuego y no quemarse". En él reconoce a su retoño y se inquieta que, en virtud del anormal privilegio, su hijo no descubriese "su condición de mero simulacro". En ese momento, un incendio expone al soñador a las llamas que, pese a envolverlo, no le dejan llagas. Así, "[c]on alivio, con humillación, con terror, comprendió que él también era una apariencia, que otro estaba soñando" (851).

\section{La mise en abyme onírica}

El cuento de Borges expone la ficción de un sueño al interior de un sueño que, al modo de una matrioska interminable, introduce la proyección al infinito de sueños dentro de sueños contenidos en otros sueños, hasta desdibujar lantes" (844). Evidentemente, la "invisible" versión menardiana del Quijoteos límites entre realidad y estado onírico. Se trata, por cierto, de un frecuente recurso borgeano a antinomias lógicas que, originalmente pronunciadas en Elea, fueron el objeto privilegiado del trabajo de Whitehead y Russel. De hecho, este último es mencionado en otro cuento que, mediante un recurso semejante, relata la improbable empresa de "Pierre Menard autor del Quijote", quien se esfuerza en "producir unas páginas que coincidieran - palabra por palabra y línea por línea- con [aquellas] de Migue de Cerv es idéntica al Quijote, aunque no por ello menos disímil al escrito del Manco de Lepanto. Por supuesto, no se trata de una transcripción del Quijote efectuada por Menard -cosa que el narrador rechaza explícitamente-, sino del Quijote del Quijote, es decir, del Quijote que -por escribirse en otro tiempo, con otra mano y, sobre todo, después del mismo Quijote- es una suerte de meta-Quijote. Sin embargo, ello no elimina el hecho de que el asombroso e invisible Quijote simplemente coincida -he ahí la ambición de su autor- con el mismísimo Quijote de Cervantes, determinando que ningún metatexto pueda venir a resolver texto alguno pues el primero no es de ninguna manera distinto del segundo. Objeción casi gödeliana a la Principia Mathematica que, agregando a un solo texto infinidad de textos superpuestos, da lugar a "una especie de palimpsesto" por el cual se subvierten las sucesiones temporales para, dice Borges, "recorrer la Odisea como si fuera posterior a la Eneida" (847).

Mise en abyme que Borges también introduce en "Las ruinas circulares" para provocar un enigmático pliegue onírico anunciado desde el epígrafe -"And if he left off dreaming about you..." (848)- extraído de un pertinente episodio de $A$ través del espejo de Lewis Carroll. En efecto, en el capítulo IV del segundo volumen de las aventuras de Alicia, Tweedledee sugiere a la niña que el dormido Rey Rojo la sueña a ella, agregando la referida expresión: "Y si dejara de soñar contigo, ¿donde crees que estarías?" (196). Alicia se desentiende afirmando que, por supuesto, ella va a estar precisamente donde está ahora; ante lo cual Tweedledee le rebate que, en tanto ella no es más que "un objeto" \{a sort of thing en el sueño del Rey Rojo, al despertar este "te apagarías, itss!, iigual que una vela!". Indignada, Alicia replica, pero Tweedledum sanciona su inexistencia real si no es tan solo como "objeto de su sueño" (197). Llorando, Alicia insiste ser bien real, mientras los gemelos desrealizan hasta sus lágrimas para culminar el episodio con una nueva afirmación de la realidad únicamente en el pensamiento: Alicia pregunta si 
va a llover y, ante la sola mención de la lluvia, los hermanos se guarecen presurosos bajo un paraguas (198).

Pero el asunto solo concluye hacia el final del libro. En el último capítulo titulado "¿Quién lo soñó?", Alicia ha despertado $y$, aún incomoda ante el sueño del Rey Rojo, le comenta a su gato: "Y ahora, Mino, pensemos quién fue el que soñó todo esto [...]: o fui yo o fue el Rey Rojo. El, por supuesto, figuraba en mi sueño, pero también yo figuraba en el suyo. ¿Existió el Rey Rojo, Mino?" (285). Con ello, los soñantes son enfrentados cual espejos para reunir sus sueños en una interminable circularidad, donde el sueño de Alicia sueña el sueño del Rey Rojo que, a su vez, sueña el sueño de Alicia que, por su parte, sueña el sueño del Rey... Así, el insensato epígrafe de "Las ruinas circulares" deja reverberando en el cuento no solo el inquietante dispositivo de una suerte de matrioska onírica infinita, sino también la ominosa posibilidad de una incesante circularidad, donde el creador onírico y la criatura soñada se encuentran enfrentados en su especular semejanza para que la segunda sea obra del primero al mismo tiempo que este producción de aquella.

Esta circularidad sin fin, variación autocontenida de la sucesión incesante de matrioskas, aparece frecuentemente en los escritos de Borges. De hecho, en "El jardín de senderos que se bifurcan" -la laberíntica novela de Ts'ui Pên donde todas las posibles variantes de un hecho ocurren y, a su vez, comportan otras múltiples variaciones que también suceden- se insiste en las contingencias del relato que, siendo una variante más de la novela que es, ella misma, el cuento cuyos títulos son exactamente idénticos a esta, imprimen al conjunto una circularidad incesante, la que es sugerida en el escrito mismo, tanto por la ocurrencia de "un volumen cíclico circular [...] cuya última página fuera idéntica a la primera [y] con posibilidad de continuar indefinidamente" (871), como por el recuerdo de aquella noche al medio de Las mil y una noches donde "la reina Shahrazad (por una mágica distracción del copista) se pone a referir textualmente la historia de Las mil y una noches, con riesgo de llegar otra vez a la noche en que la refiere, y así hasta el infinito" (871).

La mencionada noche 602 también es aludida en "Magias parciales del Quijote", donde se agrega el comentario respecto de su inquietante estructura que "duplica y reduplica hasta el vértigo la ramificación de un cuento central en cuentos adventicios" (43). Además, Borges suma al cortejo otros no menos celebres consortes como la obra al interior de la obra que, en el acto III de Hamlet, representa aproximadamente la tragedia de la cual forma parte, o bien los personajes de Cervantes leyendo a Cervantes, o incluso el propio Cervantes leyendo a Cervantes en el manuscrito árabe hallado en Toledo que, según se indica, es precisamente el Quijote (42-43).

\section{El enigma del sueño en el sueño}

Pero no olvidemos que nuestro interés se limita al sueño y, más particularmente, al sueño dentro del sueño según consta en "Las ruinas circulares". Se objetará que dicho cuento no relata un sueño en el sueño, sino más bien al sueño de uno articulado al sueño de un otro. Sin embargo, la objeción desconsidera que, en el demiúrgico universo narrativo del relato, el soñador 
no solo es un sueño, sino que su propio sueño es, sin duda, un sueño dentro del sueño de aquel que, a él, lo sueña. Se trata, justamente, de la fundada pregunta de Alicia -¿quién lo soñó?-, pues sea quién sea que sueñe, en ambos casos el sueño de uno será siempre un sueño dentro del sueño del otro.

En la Interpretación de los sueños, Freud se enfrenta al "enigma del 'sueño en el sueño'" (342), indicando que este es equivalente a la desestimación del sueño contenida en la declaración: "esto no es más que un sueño". Lejos de fascinarse con la mise en abyme onírica, Freud no dice que la vida sea un sueño, sino que, en el sueño mismo, la realidad irrealiza lo soñado. Para Freud, en efecto, el misterioso recurso onírico buscaría "desvalorizar lo 'soñado', arrebatarle su realidad \{Realität\}", pues el despertar dentro del sueño lo indica como meramente soñado. No obstante, por cuanto la desestimación no es externa al sueño, sino parte integrante de este, entonces lo soñado en el sueño contiene "la figuración de la realidad borrada \{Darstellung der Realität\}, el recuerdo real \{die wirkliche Erinnerung\}, y el sueño que sigue, al contrario, la figuración de lo que el soñante meramente desea" (343). Así concluye Freud, cuando el trabajo del sueño sitúa un hecho como siendo sueño dentro del sueño, "ello implica la más decisiva corroboración de la realidad \{Realität\} de ese hecho, su más fuerte afirmación \{Bejahung: decir sí\}" (343).

Pero esta afirmada realidad no parece ser aquella en virtud de la cual se articula el principio de realidad (Freud "Formulaciones" 225). En efecto, la palabra que Freud utiliza en aquel pasaje no es Wirklichheit, es decir, la realidad eficiente que, en el acaecer psíquico, comanda las consideraciones del mencionado principio en virtud del cual, precisamente, se desestima a sueño como siendo solo un sueño. Diversamente, el texto de Freud le concede el privilegio al menos corriente término Realität que, en virtud de su raíz latina res, hace resonar la Cosa en su porfiada inadecuación al intelecto, además de ser el vocablo que, en el capítulo 7 de la Interpretación de los sueños, es convocado para indicar la Otra escena del inconsciente como lo psíquico estrictamente real, o sea como aquella Otra realidad $(600,607)$. De hecho, si por indicar como soñado un fragmento de sí mismo, el sueño proscribe una realidad, incluso en sueños, rechazada, entonces el sueño dentro del sueño concierne una realidad doblemente impugnada: refutada por la realidad como sueño y proscrita por el propio sueño hacia un más alla de sí. En otras palabras, el sueño en el sueño designaría una realidad que, recusada por la realidad en el sueño, se señala más allá de la realidad y del sueño. Una realidad $\{$ Realität $\}$ allende la realidad $\{$ Wirklichheit $\}$, la cual es precisamente aquello que, para Lacan, concierne radicalmente al registro de lo Real ("La psychanalyse" 354) ${ }^{1}$.

Podría parecer improcedente relacionar la escritura de Borges con la obra de Freud Sobre todo teniendo en cuenta el desprecio que el primero parecía tener por el segundo. No obstante, para la situación del sueño en "Las ruinas circulares", la indicación freudiana no parece impropia. De hecho, ella no designa otra cosa que el efecto de la escena en la escena de Hamlet, referida

1 Nota del editor. Cf. supra "Palabra previa" n. 4 
por Borges mismo. Pues la pequeña pieza actuada en la obra no hace otra cosa que revelar, con rústica evidencia, la realidad de la cual el protagonista no ha logrado o, mejor aún, no ha querido hacerse cargo. Como lo subraya Lacan, la mencionada escena, lejos de apuntar hacia una realidad cuya denuncia atraparía la conciencia del rey, concierne otra realidad que, vinculando a Hamlet con Ofelia en virtud del oscuro objeto freudiano del duelo, convoca el deseo del protagonista, más allá del juego especular entre los rivales, al lugar "de la víctima, de la suicidada, manifiestamente ofrecida en sacrificio a los espíritus de su padre" (La angustia 47).

En tal sentido, como lo indica Eduardo Sabrovsky a propósito de otro cuento de Borges, "la puesta en abismo borgeana", sea en su proyección al infinito o en su circularidad interminable, representa un "dispositivo que pretende abrir paso a un desfondamiento más primordial de la experiencia" que "[p]or la vía de la autorreferencia y su efecto abisal", introduce una "apelación a lo Real" en virtud del cual se "exige el abandono del "círculo mágico de la existencia' [...] para acceder a una Verdad Otra" (204-205).

\section{La falta de olvido}

Pero ¿verdad o realidad? La pregunta no es ingenua, ni mucho menos retórica. Para Lacan, la verdad y lo real no se recubren enteramente, pues si la verdad, aun cuando a medias, habla ("La chose..." 406), lo real se soporta, en tanto "imposible a decir", a nivel del límite mismo de la palabra ("C'est à la lecture..." 14). En efecto, no hay verdad que, sobre el lenguaje, no haga reposar su garantía y es, justamente, por ello que ella se enuncia e, incluso, se denuncia. De hecho, por su dependencia al significante, la verdad instituye en la ficción su estructura ("Subversion" 288), comprendiendo también con ello su condición de jamás decirse toda ("Télévision" 509). Pues si en el Otro un significante falta y, precisamente, aquel capaz de decir la verdad del Otro; entonces ninguna verdad es apta a ser dicha entera, sino solo en ficciones decirse a medias.

Asunto interesante en cuanto a literatura respecta y que el propio Lacan subraya al indicar que "la obra literaria es, en tanto ficción, estructura verdadera" ("C'est à la lectura" 16). Pero asunto, quizás, aún más relevante para la narrativa borgeana, donde la ficción parece brotar, como en el "Menard autor del Quijote", de aquella precisa inconsistencia del Otro que, según Lacan, recusa cualquier Otro del Otro y, particularmente, aquel de un lenguaje que, en calidad de metalenguaje, se pretenda más allá del lenguaje ("Subversion" 293).

Más fugaz y menos estable, la verdad para Lacan está lejos de resolverse en la adaequatio rei et intellectus. Muy por el contrario ella surge de una total inadecuación que, precisamente, emerge en la ficción y, particularmente, en las ficciones propias del sueño y del síntoma. De hecho, este último es definido como "ser-de-verdad" ("Problèmes cruciaux" 201) y, por cierto, lo propio puede ser dicho del sueño cuya interpretación es, como Freud lo indica, via regia al discernimiento de lo inconsciente (La interpretación 597). En tal sentido, Lacan retoma el platónico motivo de la verdad como alétheia, pero no en el sentido heideggeriano del desocultamiento, sino en 
uno quizás más ficcional y centrado en su "falta-de-olvido" (L'envers 58). En efecto, la verdad descamina los divinos senderos de Leto, la diosa griega del olvido, y precisamente es ello lo que su nombre indica: a-létheia, sinolvido. Consistentemente, el síntoma -pero, quizás, aún más el sueño- es en tanto ficción de lo inconsciente, el retorno de una verdad desoída, una falta de olvido.

Pues bien, en "Las ruinas circulares", el sueño en el sueño se encuentra cubierto por la desmemoria, mientras que su reencuentro es, justamente, la disolución de un olvido. En efecto, el cuento relata como el soñador infunde la amnesia en su retoño onírico sin saber que, con ello, repite el gesto que, realizado por aquel del cual él es sueño, le ha dejado igualmente ignorante de su propio nacimiento como hijo soñado. El encuentro con el recuerdo de su origen gracias al destino escuchado de su onírico crío, es precisamente el momento en que, discernido el sueño de otro, emerge la pieza capaz de colegir su sueño como un sueño al interior de un sueño. Llevado al exacto punto del sueño en el sueño, su propio sueño es falta-de-olvido.

\section{El ominoso deseo del Otro}

Verdad, por cierto. Pero ¿y lo real? ¿Por qué Freud subraya aquí la Realität? Pese a que real y verdad no se recubren, ello no los condena a su completo desencuentro e, incluso, nada impide a lo real acontecer en la dystychia del mal encuentro (Lacan, Les quatre concepts 67, 76, 237). En efecto, Lacan señala que no solo la ficción nada tiene de ilusoria ni engañosa, sino que la ficción verídica admite la indicación de lo real ("Compte rendu"12). De hecho, la inconsistencia del Otro, aquello que Lacan designa como el significante de la falta de un significante en/del Otro $\{\mathrm{S}(\mathrm{A} / \mathrm{l})$ ) $\}$ por el cual se cuestiona toda pertinencia de algún metalenguaje, implica justamente que lo simbólico, al no recubrir el conjunto de lo real, contiene aquel punto de inscientia en el que se indica su límite en lo real (Le transfert 186).

Y ¿qué real, entonces? La pregunta nos deja desvalidos, pero es precisamente en el desamparo, en el sin-recursos de la Hiflosigkeit freudiana (Freud, "Inhibición" 155-157), que hemos de encontrar su respuesta. En efecto, en "Magias parciales del Quijote", Borges subraya la perturbación que nos producen semejantes artificios narrativos, preguntándose " $i[p]$ or que nos inquieta que don Quijote sea lector del Quijote, y Hamlet, espectador de Hamlet?" (44). Se trata, ciertamente, de aquella inquietante extrañeza que, bajo el término Unheimlich, Freud entendía como aquello familiar de antaño que, bajo el efecto de la represión, amenaza oculto y secreto desde lo inconsciente ("Lo ominoso" 241, 246).

Para Borges, la singular intranquilidad surge de la intuición de que "si los caracteres de una ficción pueden ser lectores o espectadores, nosotros, sus lectores o espectadores, podemos ser ficticios" ("Magias" 44). Ello no necesariamente resulta contradictorio con la Unheimlich freudiana, pero sí nos vuelve nuevamente al problema de la ficción y, en apariencia al menos, nos deja sin herramientas ante la cuestión de lo real. Sin embargo, en "Las ruinas circulares" no se trata de ficticios lectores leyendo la ficción que los narra, sino de soñantes que, al ser ellos mismos soñados, tienen sueños soñados 
en sueños de otros. ¿Podemos decir que, aquí, la inquietud provendría de una intuición sobre la posibilidad de ser, también nosotros, sueños dentro de sueños? No obstante, entre lectura y sueño existe una brecha que impide la entera aplicación de la solución borgeana, pues, más allá de la metáfora, leer no es soñar y los personajes del cuento no leen ni son leídos en sus sueños.

A decir verdad, la eventual solución no reside tanto en la estructura formal del artificio narrativo, como en su contenido estricto. En efecto, en el cuento, el soñar es -lo dice el propio Borges- un asunto de deseo: el protagonista se empeña en soñar y añora la realización de su empresa onírica. En este punto, Borges es por entero freudiano, pues el sueño del cuento es la realización de un deseo que, en la ocasión, concierne al deseo de un hijo. De ello se sigue que, si el sueño es un sueño en el sueño de otro, la realización del deseo de un hijo está contenida en la realización de un otro deseo de hijo, donde el hijo deseado es el soñante.

Pero dicho así, pareciera resonar en el relato la conocida fórmula lacaniana según la cual "el deseo del hombre es el deseo del Otro" (La direction" 106) o, incluso más borgeanamente, el deseo del sujeto es "deseo del deseo del Otro" (Le desir 566). Por cierto, lo que interesa aquí no es la frase, sino lo que ella implica, a saber, la posición en la cual se encuentra el sujeto, en el origen mismo del deseo que lo habita, en tanto situado en el lugar de un objeto real en el deseo del Otro. En palabras de Lacan: "es como objeto a del deseo, como aquello que él ha sido para el Otro en su erección de viviente, como el wanted o el unwanted de su venida al mundo, que el sujeto es llamado a nacer para saber si quiere lo que desea" ("Remarques" 160).

Pues bien, es precisamente aquella posición de objeto causa o, incluso, plus de goce, es decir, de objeto a en el deseo del Otro, lo que Lacan discierne como el fundamento último de la Unheimlich freudiana (La angustia 63). Reducido a no ser más que un objeto en las temibles fauces del deseo del Otro, el sujeto queda expuesto al Otro sin recursos, es decir, sumido en el desamparo de la Hiflosigkeit freudiana (Le désir... 502). Si, en el cuento, el soñador descubre que, al igual que su propio hijo, él se encuentra, como dice el tango, siendo el mísero ratón en el juego del gato Maula, entonces el soñador no solo se enfrenta al desamparo ante aquel deseo que lo amasa, sino que su propio deseo se articula al deseo de aquel que la vida le otorga.

He ahí lo real que parece ser convocado en la ficción del cuento: la reconducción del sujeto al lugar que, en su propio origen, ocupó en tanto objeto de/ en el deseo del Otro. Mientras que nosotros lectores nos intuimos, mediante la ficción del cuento, no tanto como ficciones, sino más bien como aquel poco de realidad que, en tanto objeto, hemos sido de los oscuros deseos de aquellos en los cuales nuestros propios deseos encontraron su origen. Aunque, para ser también borgeanos y no solo lacanianos, deberíamos conceder que, igualmente, la ficción nos mueve a intuirnos como ficciones o, mejor dicho, como sueños que, en cuanto tales, son ficciones del deseo inconsciente. Pero ello bajo la condición de que, en su margen, la ficción sepa indicar un irreal que, en su irrealización, extraiga del olvido un real capaz de conmover nuestra realidad acostumbrada. Si las ficciones borgeanas nos remecen por 
sugerirnos siendo ficciones, en ello habría que indicar que en ellas adviene una verdad inquietante por lo real que sugieren.

\section{Epílogo: la pregunta de la Esfinge}

Pero más freudianamente hablando, esta inquietante posición en lo real de un Otro deseo, en el cuento concierne directamente el deseo de un padre o, más exactamente, la infantil y bien sexual pregunta por el origen de sus retoños. En efecto, si al decir de Freud, la famosa pregunta de la Esfinge de Tebas no hace otra cosa que formular la interrogante a la inversa, es decir "¿que es, entonces, lo que viene?" (Federn \& Nunberg, 114), el cuento de Borges formula la misma pregunta pero vuelta nuevamente al anverso. Pues si, en un comienzo, la sucesión de soñantes se proyecta hacia delante y el padre sueña al hijo que, llegado su turno, como padre soñará también un hijo, el final del cuento subvierte la sucesion de padres para, como en la pregunta de los niños, proyectarla en tanto enigma hacia el origen. De hecho, la mencionada Esfinge pareciera no estar ausente en el cuento $y$, con $i$ aunque $\sin n$ ni $s$, toma la forma de la efigie que, como el temible demonio tebano, es igualmente un ser compuesto: ni mitad león ni mitad mujer, sino algo tigre y algo potro. Con ello, el cuento de Borges mantiene intacta la infantil interrogante por el origen de los niños, frente a la cual la respuesta es también la de un niño, aquella que Twedledee entrega a Alicia: los niños vienen de la potencia del padre que los sueña, sin con ello dar cabida a la sexual diferencia. Niño fálico, por cierto, cuya universalizante ficción Alicia, magnífica mujer-niña, recusa afirmando, más allá de la fálica imagen, su sexual y singular contingencia. 
